\title{
New techniques for the rapid repair of levee breaches
}

\author{
S. J. Boc, D. T. Resio \& E. C. Burg \\ US Army Corps of Engineers, \\ Engineer Research and Development Center, \\ Coastal and Hydraulics Laboratory, USA
}

\begin{abstract}
Levee breaching is a widespread issue that has had few technological improvements in history. Recent severe flooding situations have created a critical need for a rapid levee repair capability that can function in a wide range of different environments. For levee repair capabilities to make a substantial difference in interior flood levels and damages, they must act very quickly and minimize the chance of additional "unraveling" along the levee. A successful technology must be capable of functioning in extremely austere situations with little conventional logistics support and little or no site preparation. One alternative is to use the one resource readily available during floods; water, as the main structural element in conjunction with high-strength fabrics. The incompressibility of water in a closed high-strength fabric tube can create a stable geometric configuration capable of resisting deformation through a breach. In September 2008 three concepts for levee repair and protection were tested and demonstrated in a 1:4 scale physical model at the Hydraulic Engineering Research Unit, Agricultural Research Service in Stillwater, Oklahoma. Test results will be discussed.
\end{abstract}

Keywords: levee breach, high strength fabric, levee breach repair.

\section{Introduction}

Hurricane Katrina was a prime example showing how coastal and inland areas are vulnerable to natural and/or man-made disasters related to levee/floodwall breaching. This situation has created awareness for the need of a rapid levee repair capability that is adaptable to a wide range of environments (US Gulf 
Coast, Lake Okeechobee, Sacramento River, etc.). Significant complications such as time, site access, forces, irregular breach shapes, and remaining levee stability are all critical factors in developing technologies to address this problem. Three concepts for levee repair and protection were tested at the 1:4 scale in Stillwater, OK, USA.

Rapidly Emplaced Protection for Earthen Levees (REPEL) would be emplaced prior to a flood to provide protection to a levee/dam section from overtopping in extreme flood events. The Portable Lightweight Universal Gasket (PLUG) would be used for the repairs of the narrow deep breach which are typical of river levee failures and surge-driven breaches in large earthen levees. Repair of long shallow breaches is accomplished using a modified version of the PLUG. This technology is applicable when storm-induced breaching of navigation and drainage channel levees/floodwalls in coastal areas occurs, as well as overtopping of long stretches of levees along flooding rivers.

\section{Large-scale model testing and demonstration}

A review of available facilities which can generate large flow rates suggested that the optimal site for testing concepts at a large scale was the Hydraulic Engineering Research Unit (HERU) of the Agricultural Research Service in Stillwater, Oklahoma (Figure 1). This facility can maintain a flow rate of 125 cubic feet per second for prolonged periods of time.

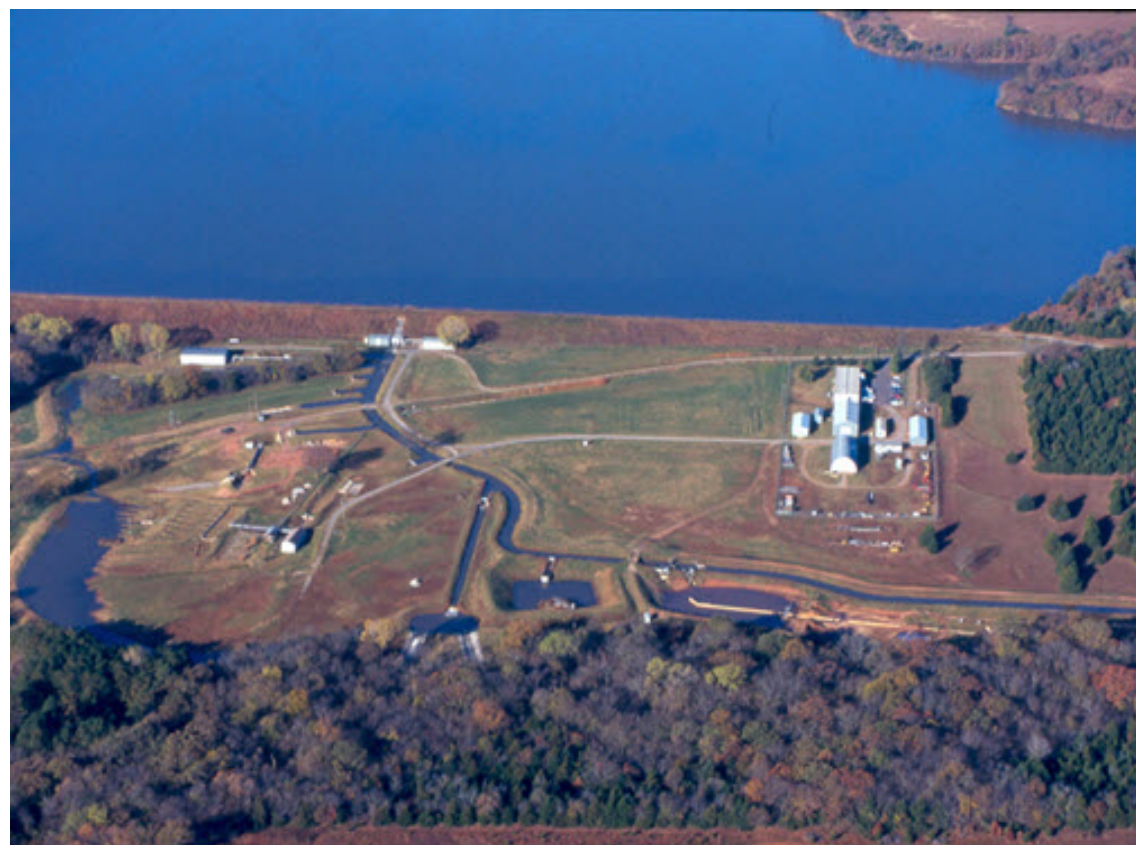

Figure 1: Aerial photo of facility at ARS-HERU facility in Stillwater, Oklahoma. 
Three different concepts were tested in the ARS facilities: 1) Rapidly Emplaced Protection for Earthen Levees (REPEL); 2) Portable Lightweight Universal Gasket (PLUG); and 3) Repair of Long Shallow Breaches - a modified version of the PLUG. Concepts 2 and 3 were previously tested successfully in the 1:16 scale tests at ERDC, while concept 1 was not tested at the smaller scale.

\section{Rapidly emplaced protection for earthen levees (REPEL)}

In many situations, earthen dams can be endangered by high flows over unprotected surfaces. In these situations, it is often not advisable to attempt to block the entire flow, since this will simply produce an additional rise in the water level behind the dam which would then threaten still other areas. Instead, if the water is allowed to pass over the surface but the surface is protected from erosion, catastrophic erosion could potentially be avoided. Figure 2 shows the system being tested at the Stillwater site. The longitudinal tubes provide adequate ballast to prevent the tarp from lifting off of the surface and washing away. The system shown here was constructed by Kepner Plastics, a fabricator of many marine applications of fabric construction located in Torrance, California, using PVC coated polyester material. The material used here weighs approximately 27.5 ounces per square yard, which made the entire system able to be moved manually by a relatively small crew of three persons. It is envisioned that the type of system shown in Figure 2 can be installed by hand in connectable sections, even over fairly large areas (hundreds of feet across); however, the scale tested and shown here was designed for functionality only up to a flow that

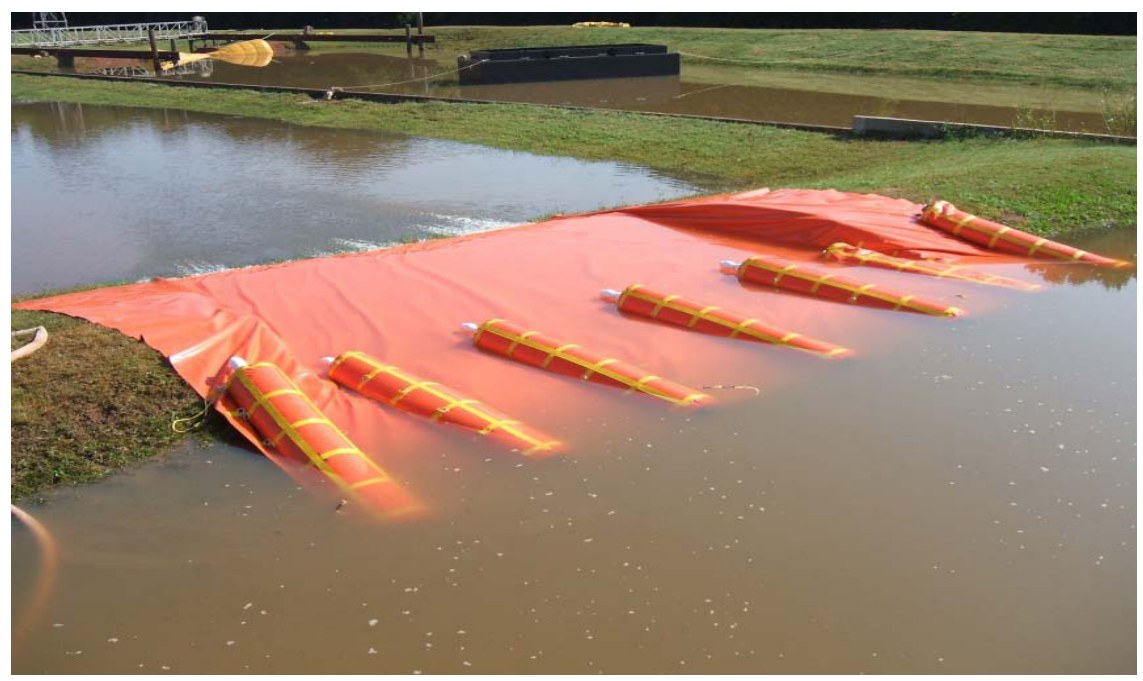

Figure 2: Demonstration of REPEL system with 0.5 -ft of water passing over the top of the breach. 
is approximately 1 foot above the surface. The performance of this system was clearly a success in terms of both its ease of deployment, ability to maintain its position, and its ability to prevent erosion of the underlying cover.

\section{Repair of long shallow breaches}

The 17th Street Canal breach in New Orleans attained a width of about 400 feet during Hurricane Katrina. This type of breach represents a particularly difficult challenge to any solutions which rely on remaining levee sections to either side of the breach for support, since the span distance becomes so large. It should be recognized, however, that the breach did not cut down to the base level of the canal anywhere along this 400-foot opening; thus, a remnant structure existed below the crest of the breach that affords an effective support which can be utilized by a system that resists vertical deformation. Figure 3 shows a picture taken of the performance of the shallow, wide breach closure system during the Stillwater demonstration. The lack of curvature of the tube along the breach in this photo indicates that the tube is not relying on the sides of the breach for support. Figure 4 shows a contrasting concept which does depend on the sides of the breach for support; and as can be clearly seen in this second photo, a catenary shape forms which is indicative of tension support along the tube from the edges of the breach. The performance of this system was deemed to be very successful in terms of its ability to adapt to the bottom shape and shut off essentially all of the flow through the breach.

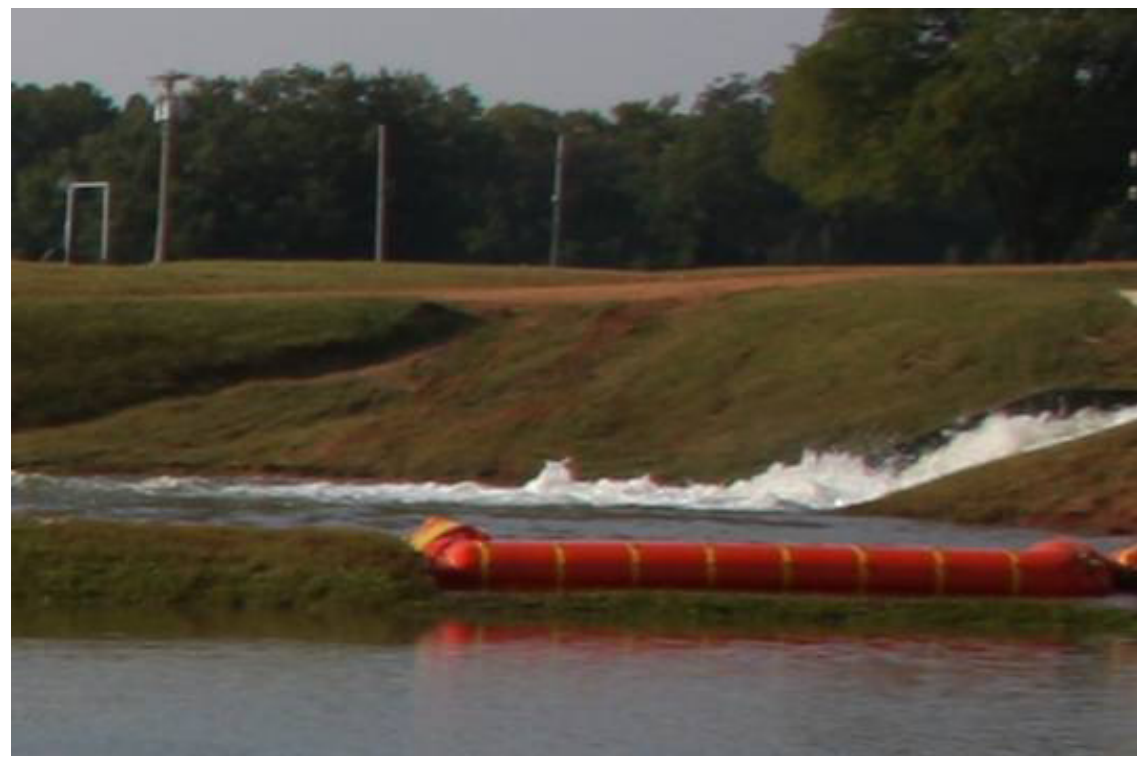

Figure 3: Demonstration of shallow, wide breach closure system. 


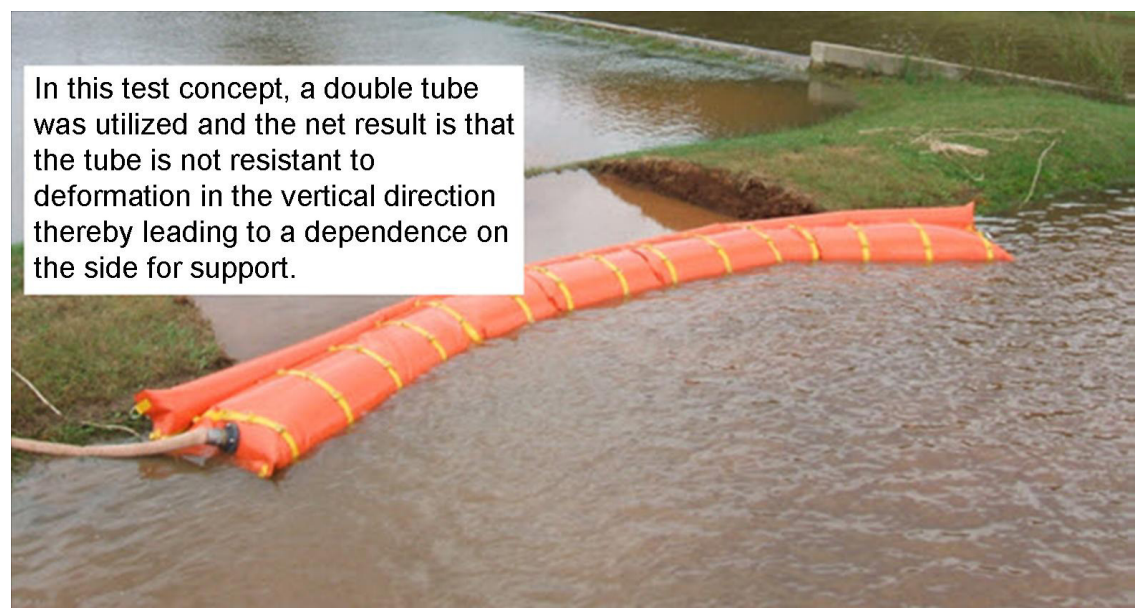

Figure 4: $\quad$ Example of wide, shallow test at Stillwater for a system which was not resistant to deformation in the vertical dimension.

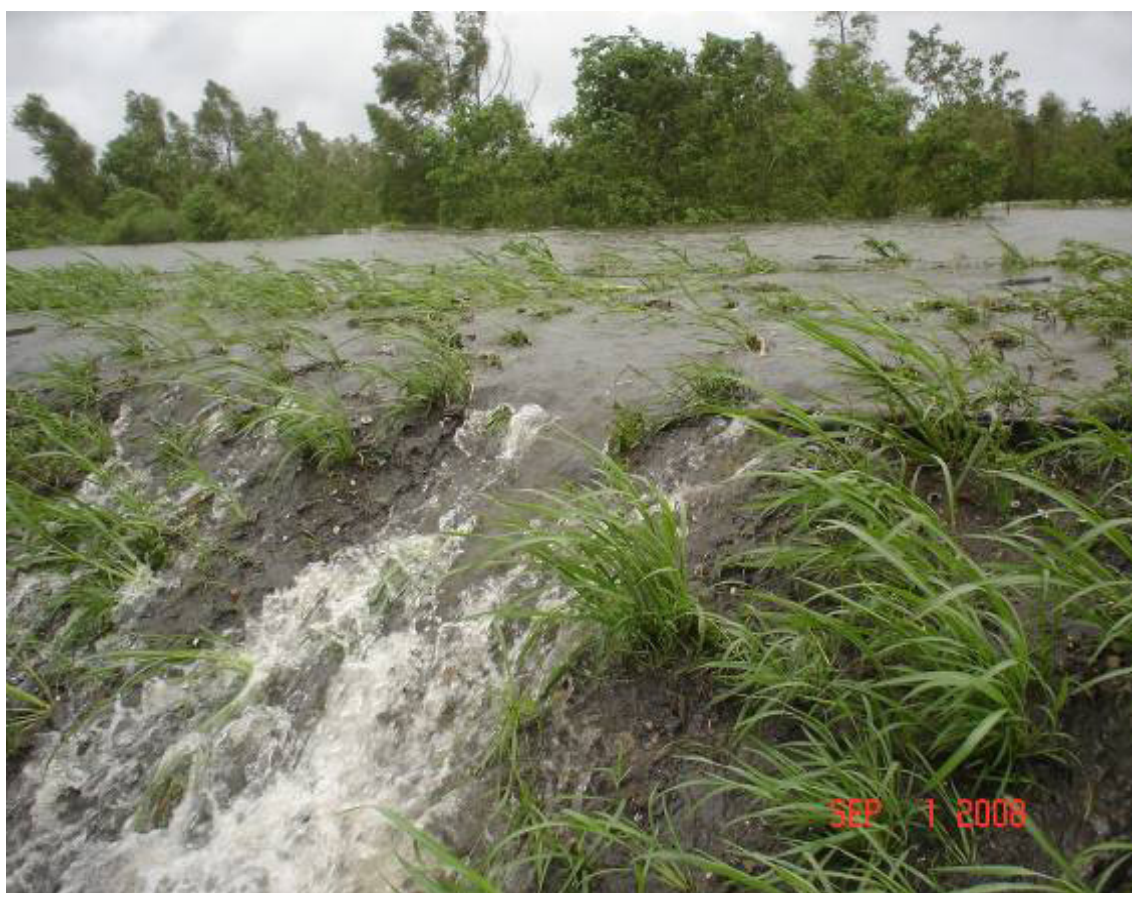

Figure 5: Close-up photograph of levee overtopping in Braithwaite, Louisiana during Hurricane Gustav. 


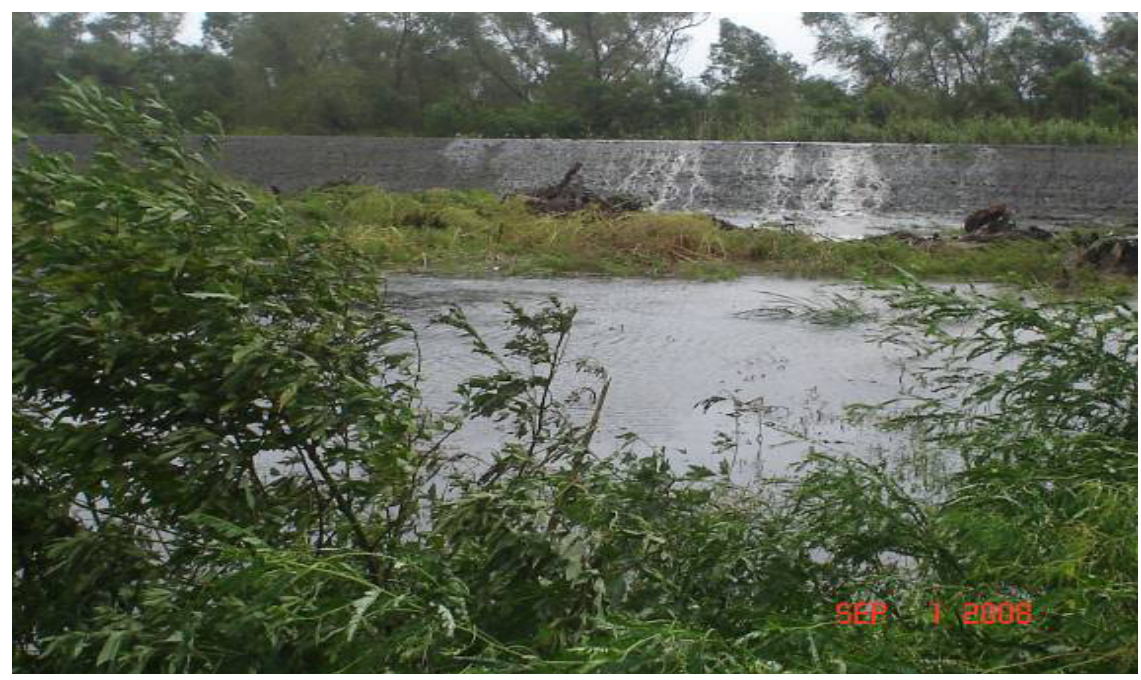

Figure 6: Wider perspective of this flow from Figure 5.

The ability of this system to prevent flow through a wide, shallow breach could be very important in many applications throughout the world. It should be recognized that such a system could be pre-positioned along low lying areas or deployed in a situation such as occurred at Braithwaite, Louisiana during Hurricanes Gustav and Ike (Figures 5 and 6). In both of these situations, weather conditions would have permitted the deployment of a water-filled fabric system, such as that demonstrated here. Another interesting aspect of this class of system is that, by placing individual systems next to each other, very long reaches of exposed levee might be protected.

\section{Portable lightweight universal gasket (PLUG)}

The final test at the ARS facility in Stillwater was perhaps the most exciting due to the flow velocities involved. In this test, a breach that was about 8 feet wide at the top of the levee and tapered to about 6 feet wide at the bottom of the levee had approximately 125 cubic feet per second passing through it, with maximum velocities estimated to be about 6 feet/second passing in through the central portion of the breach. The estimated static load for this situation, with a water level 5 feet above the bottom of the breach is approximately 4700 pounds. The dynamic load for a fast shutdown of such a flow (consistent with allowable deflections across a 6 foot-wide span) would have been in the neighborhood of 200,000 pounds.

As had been observed during the 1:16 testing, the PLUG began to roll towards the breach starting a considerable distance away from the breach opening, indicating an interaction with the bottom. In all tests conducted, the 
total time between the initiation of rolling and the final quasi-stationary position of the tube was consistently around 10 seconds. If we assume approximately linear deceleration, the maximum dynamic force is only about 20,000 pounds, which is far less than the total static force. This slow deceleration and deformation of the tube represents a significant advantage of a highly compliant system (such as an unconstrained, partially filled fabric tube) to reduce impacts on adjacent levees and to minimize the risk of adding to the damage at the breach. It should also be noted that the contact surface between the tube and the peripheral areas of the levees and breach distribute the forces acting on the PLUG over a relatively wide area. Because the first year's test was a concept demonstration, we did not have measurements of forces on the surrounding levees, but such measurements are planned for subsequent studies.

Figure 7 shows the tube in its final location from one of the dozens of largescale tests conducted. Consistent with the performance of this system concept in 1:16 scale testing, the PLUG blocked almost all of the flow in these tests. In some of the tests a small residual flow was observed at locations along the periphery of the breach, typically either at the top outside edges of the breach or the lower outside edges of the breach. However, these flows were usually very small (less than 1 cubic foot per second). As shown in Figure 8, the addition of two small tubes on either side of the breach opening usually provided a very effective seal for all flow.

As was the case with the 1:16 tests, the large-scale PLUG maintained a good seal for extended periods of time (several hours) with no apparent degradation in performance. A spurious effect of blocking the flow through the main breach was that the water in front of the breach slowly rose over a period of several minutes while the flow in the test basin adjusted to convey the 125 cubic feet per second flow over the side weir. In these cases, the side tubes illustrated in Figure 8 played a valuable role in helping seal the breach from additional flow around the top portion of the PLUG. It is possible that the same degree of "flowblocking" could be achieved by using a higher proportion of air within the PLUG combined with a reduced proportion of water, but we did not have time to test this modification during the testing phase in Stillwater.

The performance of the deep-breach closure system was deemed to be very successful in terms of its ability to adapt to the bottom shape of the breach and shut off essentially all of the flow through the breach. As noted above, it was also quite resilient in terms of its ability to continue to block the flow even in situations when incident water levels varied. Two different methods of deployment were investigated during these tests, one with the PLUG only and a second with the PLUG attached to a barge. Clearly the first of these methods is more suitable for very austere areas, while the second might be preferable in some areas where barges are readily available in the vicinity of a breach. There was no discernable difference in the performance of the systems related to the deployment method. 


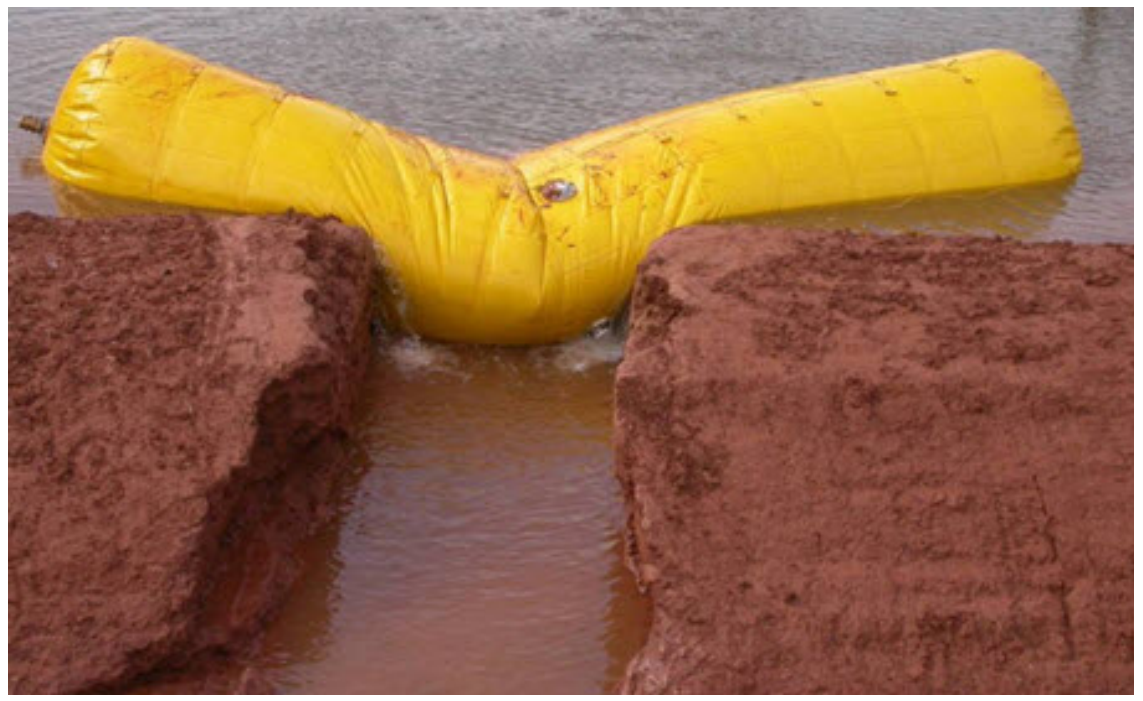

Figure 7: Sample deployment of deep-breach closure system, with a small residual flow still persisting along the upper edges of the breach opening.

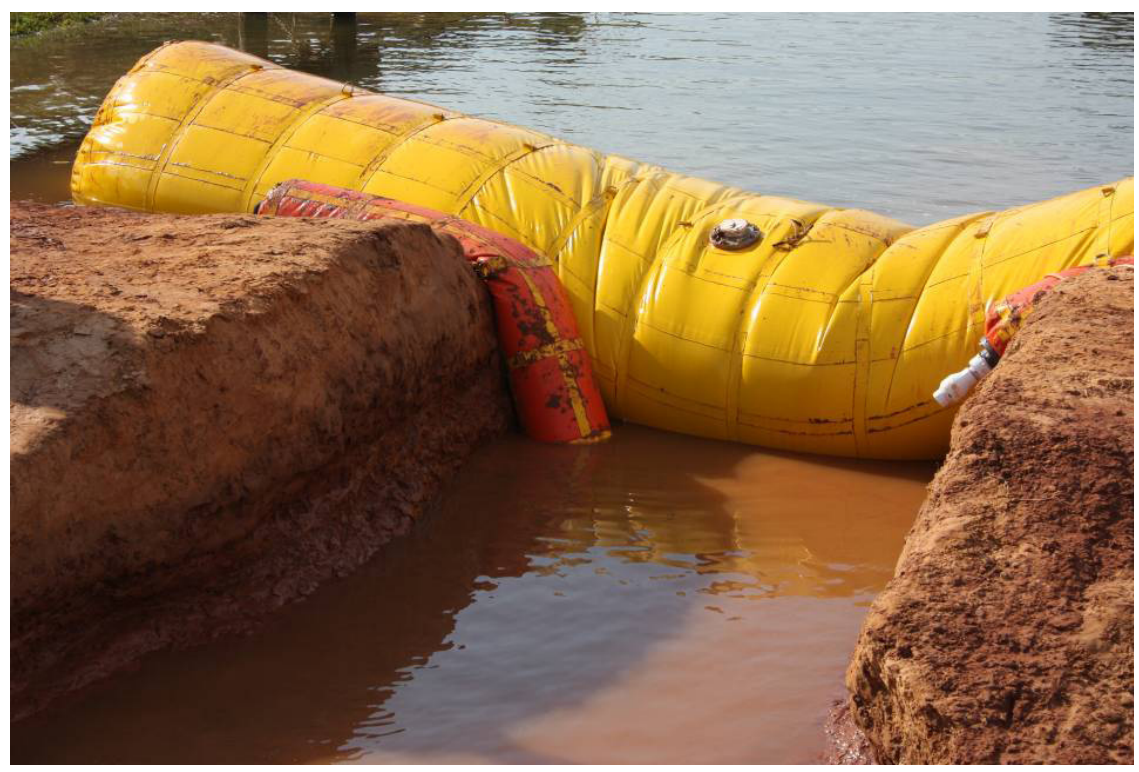

Figure 8: Sample deployment of deep-breach closure system including the addition of two small tubes along the upper edges of the breach opening which produced essentially zero-flow conditions through the breach. 


\section{Conclusions}

All three of the tested concepts were very successful at this scale. All results to date have been very encouraging, demonstrating the capability of new waterfilled fabric designs for closing breaches through which large volumes of water are flowing. We believe that we are very close to being able to rapidly repair breaches. However, it is very important to develop efficient operational guides for deploying these levee closure devices and to test this new class of rapid levee repair technology very thoroughly to verify such claims before they can be considered totally operational.

\section{Reference}

[1] Resio, D.T., Boc, S.J., Maynord, S., Ward, D., Abraham, D., Dudeck, D., Welsh. B., (2009). "Development and Demonstration of Rapid Repair of Levee Breaching Technology", Report to Department of Homeland Security. 